\title{
Assessment of flavonoids contents and in vitro antioxidant activity of Launaea procumbens
}

\author{
Rahmat Ali Khan ${ }^{1,2^{*}}$, Muhammad Rashid Khan², Sumaira Sahreen ${ }^{3}$ and Mushtaq Ahmed ${ }^{1}$
}

\begin{abstract}
Background: Launaea procumbens (LP) has been used as a food supplement in Pakistan. In this study methanolic crude extract (LPME) of the whole plant and its different fractions; n-hexane (LPHE); ethyl acetate (LPEE) and chloroform (LPCE) were studied for the determination of total flavonoid and phenolics contents along with multifaceted in vitro scavenging assays.

Results: Considerable amount of flavonoid and phenolics contents were found in all the fractions. Methanol and chloroform fraction exhibited efficient scavenging of DPPH., ABTS.+, .OH, superoxide, lipid peroxide and nitric oxide free radicals. Significant correlation was found between DPPH., ABTS.+, superoxide radical, $\beta$-carotene bleaching restraint and phosphomolybdenum assay with total flavonoids and phenolics contents. High performance chromatography (HPLC) of LPME revealed the presence of vitexin, orientin, rutin, hyperoside, catechin and myricetin.
\end{abstract}

Conclusion: These results reveal the presence of bioactive compounds in LPME, which might be contributed towards the various in vitro scavenging.

Keywords: Launaea procumbens, Scavenging of DPPH-free radicals, Superoxide radicals, HPLC, Flavonoids

\section{Background}

Reactive oxygen species (ROS) are generated in the normal metabolism of living organisms, and besides of their useful role in signal transduction; they are also involved in the dispersion of several degenerative diseases like malignant tumors, rheumatic joint inflammation, cataracts, Parkinson's and Alzheimer's disease, hypertension, diabetes, oxidative stress, tissue damages and atherosclerosis [1]. To protect the body from such effects; in addition to antioxidant enzymatic system, there are non-enzymatic biomolecules and proteins in living organisms, which act as antioxidant and free radical scavengers. However, food supplementation containing ascorbates, carotenoids, tocopherols, flavonoids and phenols play a significant role in this matter $[2,3]$. These bioactive natural compounds scavenge the reactive oxygen species and prevent free radicals to cause deterioration. They have the aptitude to scavenge oxygen-nitrogen derived free radicals by donating hydro-

\footnotetext{
* Correspondence: Rahmatgul_81@yahoo.com

'Department of Biotechnology, Faculty of Biological Sciences, University of Science and Technology, Bannu, KPK 28100, Pakistan

2Department of Biochemistry, Faculty of Biological Sciences, Quaid-I-Azam

University Islamabad, Islamabad, Pakistan
}

Full list of author information is available at the end of the article gen atom or an electron, chelating metal catalysts, activating antioxidant enzymes and inhibiting oxidizes [4-6]. Based on such a type of incredible results, interest in exploration of bioactive compounds extracted from medicinal plants was increased in recent years to replace the use of synthetic drugs, which were restricted due to side effects. On the other hand, polyphenol, used as natural antioxidants, are gaining importance, due to their health benefits for humans, decreasing the risk of cardiovascular and degenerative diseases by reduction of oxidative stress and counteraction of macromolecular oxidation $[7,8]$.

Medicinal plants are also in high demand for application of functional food or biopharmaceuticals because of consumer preferences. Launaea procumbens (LP) is one of the important medicinal plants widely distributed in waste places, vacant lots and in cultivated fields throughout Pakistan. Ayurvedic and herbal medicine prepared from this plant promote self healing, good health and longevity, as well as used as a food ingredient [9]. Traditionally, it has been used in the treatment of kidney disorders like painful urination, gonorrhea, and sexual diseases [10]. Chemical characterization showed that LP is composed of salicylic acid, vanillic acid, synergic acid, 2-methylresercinol and gallic acid [11]. These compounds have spasmogenic, 
cardiovascular, anticarcinogenic, antiinflammatory, and antioxidant properties to scavenge reactive oxygen species [12]. The present study was arranged to screen the various fractions of LP for the determination of total flavonoids and phenoilc consents, and to evaluate its antioxidant potential through scavenging of various free radicals.

\section{Results}

Phytochemical characterization

\section{Total phenolics and flavonoids contents}

Table 1 shows the presence of phenolics and flavonoids contents in various fractions of LP. The LPME possessed the highest total phenolics contents $(432.8 \pm 2.93) \mathrm{mg}$ GAE/g while n-hexane comprised of lowest total phenolics content $(188.3 \pm 2.1) \mathrm{mg}$ GAE/g extract. Maximum total flavonoid contents were recorded in LPME $(13.98 \pm 0.87)$ while the lowest concentration was present in LPHE $(4.43 \pm 0.45) \mathrm{mg}$ equivalent rutin/g of dry fraction. The extraction yield of these samples varied from $4.43 \pm 0.45 \%$ to be $16.28 \pm 0.27 \%$ with a descending order of methanol $>$ chloroform $>$ ethyl acetate $>$ n-hexane fraction. Methanol and chloroform fractions resulted in the highest amount of total extractable compounds, whereas the extraction yield with ethyl acetate and n-hexane was significantly less $(P<0.01)$ as compared to methanol and chloroform fraction.

\section{HPLC quantification of flavonoids}

The HPLC-UV chromatogram revealed the presence of six polyphenolic compounds, including kaempferol, orientin, rutin, hyperuside, myricetin and quercetin. The investigated compounds in the methanolic extracts were quantified by integration of the peak-areas at $220 \mathrm{~nm}$ using an external calibration method. Calibration curves were constructed for each standard compound. Least-squares linear regression was used to determine the calibration parameters for each of standards. The linearity of all calibration curves was determined by calculating the correlation coefficients. There were some small peaks, which could not be identified; however, based on their

Table 1 Total phenolic content in different extracts of Launaea procumbens

\begin{tabular}{llll}
\hline Sample & $\begin{array}{l}\text { Total flavonoids } \\
\text { compounds as } \\
\text { rutin equivalent } \\
\text { (mg/g dry extract) }\end{array}$ & $\begin{array}{l}\text { Total phenolic } \\
\text { compounds as } \\
\text { mg Gallic } \\
\text { acid equivalent } \\
\text { (GAE mg/g extract) }\end{array}$ & $\begin{array}{l}\text { \% yield } \\
\text { extraction }\end{array}$ \\
\hline LPME & $13.98 \pm 0.87^{\mathrm{c}}$ & $432.8 \pm 2.93^{\mathrm{c}}$ & $16.28 \pm 0.27^{\mathrm{d}}$ \\
LPCE & $7.3 \pm 0.54^{\mathrm{b}}$ & $267.4 \pm 1.3^{\mathrm{b}}$ & $10.3 \pm 0.54^{\mathrm{c}}$ \\
LPEE & $8.6 \pm 0.37^{\mathrm{b}}$ & $322 \pm 3.6^{\mathrm{b}}$ & $8.6 \pm 0.37 \mathrm{~b}^{\mathrm{b}}$ \\
LPHE & $4.43 \pm 0.45^{\mathrm{a}}$ & $188.3 \pm 2.1^{\mathrm{a}}$ & $4.43 \pm 0.45^{\mathrm{a}}$ \\
\hline
\end{tabular}

Each value in the table is represented as Mean $\pm S D(n=3)$ Means not sharing the same letter are significantly different (LSD) at $P<0.01$ probability level in each column.

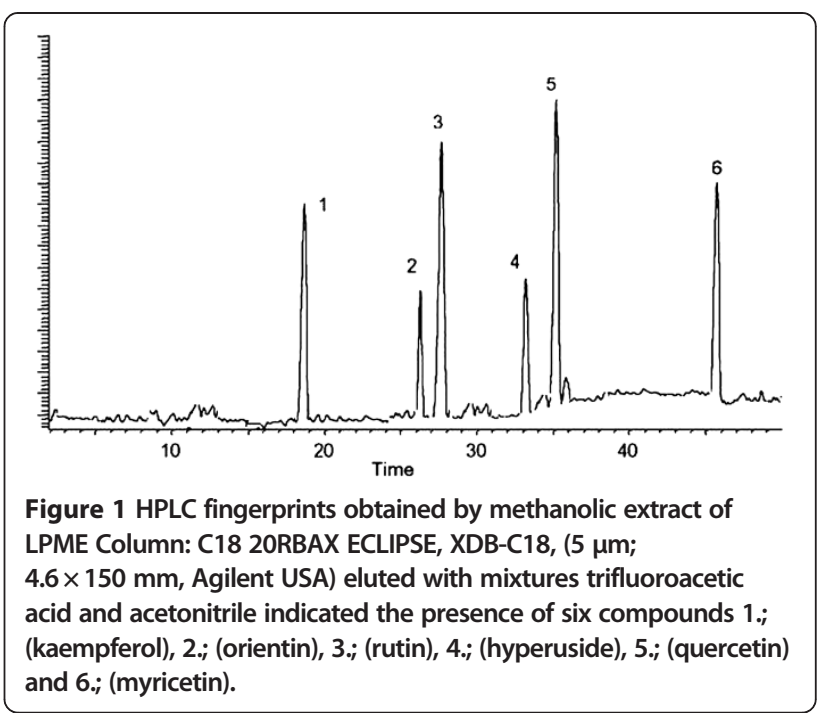

chromatographic behaviors and UV spectra, their chemical class may correspond to unknown flavonoids compounds as presented in Figure 1. The Table 2 revealed that LPME possessed highest quantity of myricetin $(1.237 \pm 0.04)$ while hyperuside $(0.335 \pm 0.06)$ are in low concentration.

\section{In vitro antioxidant assays}

DPPH (1, 1-diphenyl-2-picryl-hydrazyl) radical scavenging activity

DPPH is a stable free radical, which has been widely used in phytomedicine for the assessment of scavenging activities of bioactive fractions. The scavenging activities of various fractions of LP extracts were determined using free radicals of 1, 1-diphenyl 1-2-picryl-hydrazyl (DPPH) (Figure 2 and Table 3 ). Results showed that LPME (IC50 $2.6 \pm 0.004 \mu \mathrm{g} / \mathrm{ml}$ ) possessed the highest antioxidant activity as compared to other fractions while LPHE had the lowest scavenging effect (IC50 19 $\pm 0.04 \mu \mathrm{g} / \mathrm{ml}$ ). The DPPH radical scavenging activities of the LPME were even less $(P<0.01)$ than those of ascorbic acid.

Table 2 HPLC quantification of methanolic extract of Launaea procumbens

\begin{tabular}{llll}
\hline Samples & Retention time & $\begin{array}{l}\text { Concentration } \\
(\boldsymbol{\mu} \mathbf{g} / \mathbf{m g} \text { dry weight })\end{array}$ & Compound \\
\hline LPME & 18.5 & $0.607 \pm 0.03$ & kaempferol \\
& 26.0 & $0.725 \pm 0.02$ & orientin \\
27.5 & $0.608 \pm 0.07$ & rutin \\
33.0 & $0.335 \pm 0.06$ & hyperuside \\
35.0 & $0.897 \pm 0.05$ & quercetin \\
& 45.5 & $1.237 \pm 0.04$ & myricetin \\
\hline
\end{tabular}

Mean \pm SEM 


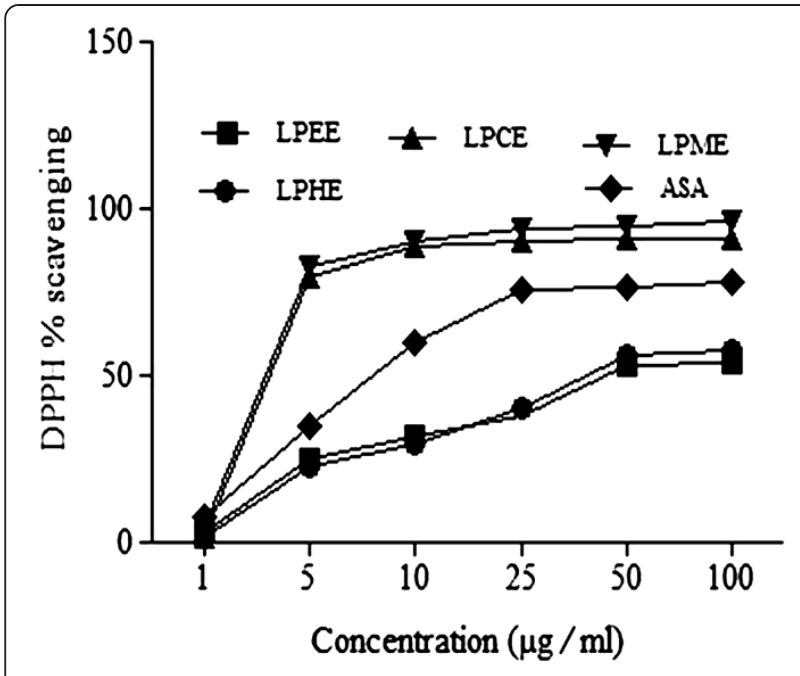

Figure 2 DPPH radical scavenging activity of different extracts from the methanol extract of $L$. procumbens by different solvents at different concentrations. Each value represents a Mean \pm SD $(n=3)$ LPHE; LPEE; LPCE; LPME; ascorbic acid.

\section{ABTS radical cation assay}

Scavenging capacities of various fractions of LP and ascorbic acid were assessed using ABTS (2, 2 azobis-(3-ethylbenzothiozoline-6-sulphonic acid) radical cation. Various fractions were found considerably different in their ABTS radical cation scavenging activities. The ABTS radical scavenging activity orders of various fractions of LP are; LPME $(50.2 \pm 1.7 \mu \mathrm{g} / \mathrm{ml})>$ LPCE $(88.5 \pm 3.8 \mu \mathrm{g} / \mathrm{ml})>$ LPEE $(104.3 \pm 6.9 \mu \mathrm{g} / \mathrm{ml})>$ and LPHE $(112.1 \pm 7.2 \mu \mathrm{g} / \mathrm{ml})$ respectively (Table 3). The results showed that LPME possessed significantly higher ABTS radical scavenging activity $(P<0.01)$ as compared to ascorbic acid $(57.4 \pm 3.1 \mu \mathrm{g} / \mathrm{ml})$.

\section{Phosphomolybdenum assay}

The basic principle to assess the antioxidant capacity through phosphomolybdenum assay includes the reduction of Mo (VI) to Mo (V) by the plant extract possessing antioxidant compounds. In the present study addition of the various fractions of LP showed that LPME (IC50 $64.27 \pm 2.1 \mu \mathrm{g} / \mathrm{ml}$ ) was more effective in reduction of Mo (VI) to Mo (V) while the lowest effects were shown by LPHE $(123 \pm 3.09 \mu \mathrm{g} / \mathrm{ml})$. The reduction of Mo (VI) to Mo (V) by administration of reference chemicals; ascorbic acid (IC50 $72.3 \pm 2.2 \mu \mathrm{g} / \mathrm{ml}$ ) (Table 3 ), suggested the presence of effective antioxidants in various fractions of LP.

\section{Antioxidant activity determined by $\beta$-carotene bleaching method}

The antioxidant potential of the various fractions of LP was arranged for screening through $\beta$ - carotene bleaching method (Table 3). The absorbance of $\beta$-carotene was found to be decreased in the presence of $50-250 \mu \mathrm{g} / \mathrm{ml}$ of the various fractions or ascorbic acid. Various fractions of LP effective inhibited the oxidation of linoleic acid and subsequent bleaching of $\beta$-carotene. Among the various fractions, LPME (IC50 $51.4 \pm 2.4 \mu \mathrm{g} / \mathrm{ml}$ ) showed greater inhibitory activity $(P<0.01)$ of $\beta$ carotene than other fractions and ascorbic acid (IC50 $54.7 \pm 3.6 \mu \mathrm{g} / \mathrm{ml}$ ). The results suggested that various fractions possessed effective antioxidant constituents.

\section{Superoxide radical scavenging activity}

Oxidation is life, but except of so many necessary processes of life, during normal metabolism of oxygen, various free radicals as well as superoxide are produced continuously. The high level of this superoxide radical is known to be harmful to cellular ingredients as, contributing to tissue damage and various diseases. The scavenging of the various fractions of LP extracts on superoxide radicals are shown in Figure 3 and Table 3. Scavenging for super oxide radicals exhibited by LPME (IC50 $70.3 \pm 2.43 \mu \mathrm{g} / \mathrm{ml}$ ) was comparatively similar to ascorbic acid.

\section{Hydroxyl radical scavenging}

Among the oxygen radicals, hydroxyl radical is the most reactive and induces severe damage to adjacent biomolecules such as protein, DNA and lipids; cause's lipids peroxidation. Table 3 shows the hydroxyl radical scavenging of the various fractions and ascorbic acid. LPME, LPEE, LPCE and LPHE scavenged hydroxyl radicals by IC50; $51.2 \pm 1.4 \mu \mathrm{g} / \mathrm{ml}, 56.4 \pm 2.0 \mu \mathrm{g} / \mathrm{ml}, 75.3 \pm 2.23 \mu \mathrm{g} / \mathrm{ml}$ and $92.5 \pm 0.56 \mu \mathrm{g} / \mathrm{ml}$, respectively. The scavenging affects of ascorbic acid (IC50; $92.5 \pm 2.56 \mu \mathrm{g} / \mathrm{ml}$ ) were significantly lower against the various fractions of LP.

\section{Hydrogen peroxide-scavenging}

Hydrogen peroxide is nonreactive, but its high concentrations are toxic to living cells, and changed into free radical called hydroxyl radicals; therefore, the scavenging affects of various fractions are evaluated against this free radical (Table 3 ). The hydroxyl free radical in the cells can easily cross cell membranes and react with most biomolecules causes tissue damage, cancer and cell death. Thus, removal of hydroxyl free radical is necessary in to protect life. Scavenging affect of various fractions with ascorbic acid showed that LPME (IC50; $63.4 \pm 3.65 \mu \mathrm{g} / \mathrm{ml}$ ) had $(P<0.01)$ highest hydroxyl radical scavenging affect and was most potent than ascorbic acid (IC50 $76.3 \pm 2.15 \mu \mathrm{g} /$ $\mathrm{ml}$ ) respectively.

\section{Chelating on $\mathrm{Fe} 2+$}

Chelation of iron plays the main role for assessing antioxidant potential of medicinal plants. The reducing power of various fractions to reduce iron ion Fe (III) into Fe (II) is shown in Table 3. Various fractions of LP showed an ability 
Table 3 IC $_{50}$ of different extracts of Launaea procumbens for various antioxidant systems

\begin{tabular}{|c|c|c|c|c|c|c|c|c|c|c|}
\hline & $\begin{array}{l}\text { DPPH } \\
\text { activity }\end{array}$ & $\begin{array}{l}\text { ABTS radical } \\
\text { Inhibition } \\
\text { assay }\end{array}$ & $\begin{array}{l}\text { Phosphomolybdenum } \\
\text { assay }\end{array}$ & $\begin{array}{l}\beta \text {-carotene } \\
\text { bleaching } \\
\text { Inhibition }\end{array}$ & $\begin{array}{l}\text { Chelating } \\
\text { activity on } \mathrm{Fe}^{2}+\end{array}$ & $\begin{array}{l}\text { Hydroxyl radical } \\
\text { scavenging } \\
\text { activity }\end{array}$ & $\begin{array}{l}\text { Super oxide radical } \\
\text { scavenging } \\
\text { activity }\end{array}$ & $\begin{array}{l}\text { Nitric oxide } \\
\text { scavenging } \\
\text { activity }\end{array}$ & $\begin{array}{l}\text { Lipid peroxidation } \\
\text { assay }\end{array}$ & $\begin{array}{l}\text { Hydrogen peroxide } \\
\text { scavenging activity }\end{array}$ \\
\hline LPME & $2.6 \pm 0.004^{a}$ & $50.2 \pm 4.7^{\mathrm{a}}$ & $64.27 \pm 2.2^{\mathrm{a}}$ & $51.4 \pm 2.4^{\mathrm{a}} 21^{\mathrm{a}}$ & $63.6 \pm 1.1^{a}$ & $54.2 \pm 1.4^{\mathrm{a}}$ & $70.3 \pm 2.43^{a}$ & $59.4 \pm 2.42^{b}$ & $60.25 \pm 4.7^{a}$ & $60.4 \pm 3.65^{a}$ \\
\hline LPCE & $17.8 \pm 0.06^{\mathrm{d}}$ & $88.5 \pm 3.8^{b}$ & $78.3 \pm 2.8^{b}$ & $94.2 \pm 2.6^{\mathrm{b}}$ & $69.5 \pm 3.0^{\mathrm{a}}$ & $56.4 \pm 2.0^{\mathrm{a}}$ & $90.5 \pm 3.6^{b}$ & $66.3 \pm 1.6^{\mathrm{a}}$ & $80.2 \pm 4.56^{b}$ & $80.5 \pm 3.0^{b}$ \\
\hline LPEE & $10.4 \pm 0.21^{c}$ & $104.3 \pm 1.9^{c}$ & $98.3 \pm 1.8^{c}$ & $125.4 \pm 1.5^{c}$ & $74.1 \pm 3.06^{b}$ & $75.3 \pm 2.23^{b}$ & $139.6 \pm 6.3^{c}$ & $99.1 \pm 3.9^{b}$ & $97.3 \pm 1.5^{c}$ & $97.6 \pm 2.3^{c}$ \\
\hline LPHE & $19 \pm 0.04^{d}$ & $122.1 \pm 5.2^{d}$ & $123 \pm 3.09^{d}$ & $190.21 \pm 2.8^{d}$ & $92.5 \pm 3.25^{c}$ & $92.5 \pm 0.56^{c}$ & $220.7 \pm 7.8^{d}$ & $145 \pm 3.2^{c}$ & $112.2 \pm 2.4^{d}$ & $100.7 \pm 3.8^{c}$ \\
\hline RT & $6.7 \pm 0.09^{b}$ & $52.7 \pm 3.2^{\mathrm{a}}$ & $58.3 \pm 1.8^{\mathrm{a}}$ & $61.6 \pm 2.4^{\mathrm{a}}$ & $75.3 \pm 3.18^{b}$ & $93.2 \pm 2.6^{c}$ & $68.6 \pm 2.3^{\mathrm{a}}$ & $68.45 \pm 4.2^{\mathrm{a}}$ & $57.4 \pm 3.1^{\mathrm{a}}$ & $86.3 \pm 4.0^{b}$ \\
\hline ASA & $3.7 \pm 0.4^{\mathrm{a}}$ & $57.4 \pm 3.1^{\mathrm{a}}$ & $72.3 \pm 2.2^{\mathrm{a}}$ & $54.7 \pm 3.6^{\mathrm{a}}$ & $65.0 \pm 2.1^{\mathrm{a}}$ & $92.5 \pm 2.56^{c}$ & $70.7 \pm 2.8^{\mathrm{a}}$ & $57.2 \pm 2.65^{\mathrm{a}}$ & $52.7 \pm 3.2^{\mathrm{a}}$ & $76.3 \pm 2.15^{b}$ \\
\hline
\end{tabular}




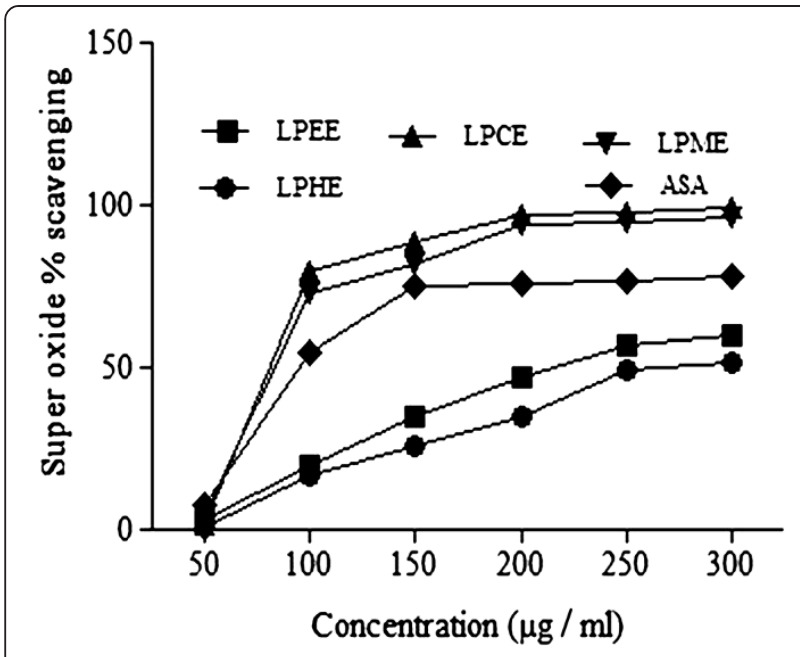

Figure 3 Super oxide radical scavenging activity of different extracts from the methanol extract of $L$. procumbens by different solvents at different concentrations. Each value represents a Mean $\pm S D(n=3)$ LPHE; LPEE; LPCE; LPME; ascorbic acid.

to chelate iron (II) ions in a dose-dependent manner. LPCE and LPME chelated iron ion (IC50; $69.5 \pm 3.0 \mu \mathrm{g} / \mathrm{ml}$; IC50; $63.6 \pm 1.1 \mu \mathrm{g} / \mathrm{ml})$, however, LPEE and LPHE chelate iron (II) ions (IC50; $74.1 \pm 3.06 \mu \mathrm{g} / \mathrm{ml}, \mathrm{IC} 50 ; 92.5 \pm 3.25 \mu \mathrm{g} / \mathrm{ml}$ ), as against the iron chelating for ascorbic acid was IC50; $65.0 \pm 2.1 \mu \mathrm{g} / \mathrm{ml}$.

\section{Lipids peroxidation assay}

Egg yolk lipids undergo rapid nonenzymatic peroxidation when hatched in the presence of ferrous sulfate. Lipids peroxides are likely involved in many pathological events, including inflammation, metabolic disorders, oxidative stress and cellular aging. The affects of various fractions of LP, ascorbic acids on nonenzymatic peroxidation are summarized in Table 3. The highest activity was remarked for LPME (IC50 $60.25 \pm 4.7 \mu \mathrm{g} / \mathrm{ml})(P<0.01)$ of LP and is more potent in inhibition of lipids peroxidation than other fractions. Antioxidant against lipids peroxidation was obtained for ascorbic acid (IC50 $52.7 \pm 3.2 \mu \mathrm{g} / \mathrm{ml}$ ).

\section{Nitric oxide scavenging}

Sodium nitroprusside in aqueous solution at physiological $\mathrm{pH}$ spontaneously produces nitric oxide, which interacts with oxygen to produce nitrite ions that can be estimated using Grries's reagent. Scavengers of nitric oxide compete with oxygen, leading to reduced production of nitrite ions. Overall, the LPME (IC50 55.4 $\pm 2.42 \mu \mathrm{g} / \mathrm{ml}$ ) showed the highest nitric oxide scavenging $(P<0.01)$ ability compared to other fractions (Table 3 ) and ascorbic acid. When the scavenging abilaty was expressed as Trolox equivalent, it showed the methanol extracts was more potent than the other fractions.

\section{Correlation with IC50 values of antioxidant and phytochemical constituents}

Correlation analysis for phytochemical contents with IC50 values of radical scavenging and/or antioxidant ability of extract of LP and its various soluble fractions. The contents of phenolics and flavonoids showed significant correlation (R2 0.6721-0.998) with DPPH, superoxide, hydrogen peroxide, phosphomolybdenum and ABTS radical scavenging (Table 4) while nonsignificantly correlated with scavenging of hydroxyl and nitric oxide radicals. In addition, IC50 of chelating power of iron presented a significant correlation with flavonoids while non significant with phenolics.

\section{Discussion}

Polyphenolic flavonoids are occurring ubiquitously in food and medicinal plants. They occur as glycosides and contain several phenolics hydroxyl groups. Many flavonoids are found to be strong antioxidants effectively scavenging the reactive oxygen species because of their phenolics hydroxyl groups [13]. Our study revealed the presence of six bioactive polyphenolic flavonoids (kaempferol, orientin, rutin, hyperuside, myricetin and quercetin) in LPME, which might play an important role in improving of oxidative stress [14]. Other studies reported the presence of the bioactive constituent during chemical characterization of medicinal plants [15-18]. The data of the present study reveal the LPME contained notable amounts of phenolics compounds endowed with high antioxidant. These findings provide a good pharmacological logic for this plant in renal injuries, hormonal and sexual disorders, and antimicrobial as well as its use in folk and herbal medicine in Pakistan. It has been reported in many investigations that bioactive fractions of different medicinal plants having free radical scavenging and antioxidant, are used in many diseases like

Table 4 Correlations between the $\mathrm{IC}_{50}$ values of antioxidant activities, phenolics and flavonoids content of Launaea procumbens

\begin{tabular}{|c|c|c|}
\hline \multirow[t]{2}{*}{ Assays $\left(\mathrm{IC}_{50} \mu \mathrm{g} / \mathrm{ml}\right)$} & \multicolumn{2}{|c|}{ Correlations $\mathbf{R}^{2}$} \\
\hline & Phenolics & Flavonoids \\
\hline DPPH & $0.9762^{b}$ & $0.8843^{b}$ \\
\hline Hydrogen peroxide scavenging assay & $0.8101^{b}$ & $0.7657^{\mathrm{a}}$ \\
\hline Super oxide radical scavenging & $0.6987^{a}$ & $0.6765^{b}$ \\
\hline Phosphomolybdenum assay & $0.7237^{a}$ & $0.7567^{a}$ \\
\hline$\beta$-carotene bleaching Inhibition & 0.2003 & 0.2060 \\
\hline ABTS radical Inhibition assay & $0.8821^{b}$ & $0.7797^{\mathrm{a}}$ \\
\hline Nitric oxide scavenging activity & 0.3212 & 0.2134 \\
\hline Chelating activity on $\mathrm{Fe}^{2}+$ & 0.3435 & 0.5564 \\
\hline Hydroxyl radical scavenging activity & 0.3454 & 0.2364 \\
\hline Lipid peroxidation activity & 0.4976 & 0.4123 \\
\hline
\end{tabular}

Launaea procumbens methanolic extract and its soluble fractions were used in the correlation. $\mathrm{a}, \mathrm{b}$ indicate significance at $\mathrm{P}<0.05$ and $\mathrm{P}<0.01$ respectively. 
cancer, tissue inflammatory and cardiovascular disease [19-22]. Also, the number of publications on the health benefits of polyphenol has been increased [23,24]. Various free radical scavenging methods used in this study are simple and have provided reproducible results showing antioxidant properties of various fractions of LP. The antioxidant capacity of different fractions observed in this experiment could be, because of the presence of high phenolics compounds. LPME is more potent compared to other fractions and found in accordance with previous reports $[25,26]$, which have shown that high total polyphenol content increases the antioxidant activity and proves a linear correlation between phenolics content and antioxidant activity. LPME exhibited a significant correlation as was reported by Bortolomeazzi et al. [27]. Phenolic compounds such as flavonoids, phenolics acid and tannins possess diverse biological activities such as anti-inflammatory, anticarcinogenic and antiatherosclerotic. The presence of these bioactive compounds might contribute to diverse scavenging effects of LP [28]. Free radicals of 1, 1-diphenyl 1-2-picrylhydrazyl (DPPH) are widely used for screening of medicinal plants to investigate their antioxidant potential. In these procedure-free, DPPH radicals when dissolves in methanol, give violet color in methanol solution. The results existed clearly indicate that in screening of various fractions of LP, methanol fraction had marked scavenging affect with IC50 $2.6 \pm 0.004$ at 50-250 $\mu \mathrm{g} / \mathrm{ml}$. Our results are supported by other investigation [29]. The potential of various fractions to scavenge free radical was also assessed by their ability to quench ABTS, and depicts that LPME possessed IC50 $(66.1 \pm 1.02 \mu \mathrm{g} / \mathrm{ml})$ value, showing the strongest activity even more than reference compounds. According to Oszmianski et al. [30], the antioxidant activities against ABTS or DPPH were correlated to the concentration, chemical structures, and polymerization degrees of antioxidants. Hagerman et al. [31] have reported that the high molecular weight phenolics (tannins) have more abilities to quench free radicals (ABTS) and their effectiveness depends on the molecular weight, the number of aromatic rings and nature of hydroxyl group's substitution than the specific functional groups. Free radical (ABTS.+) scavenging of LP fractions might be due to the presence of high molecular weight phenolics such as catechin, and rutin derivatives in addition to other flavonoids. The phosphomolybdate method has been routinely used to evaluate the total antioxidant capacity of extracts [32]. The results showed the methanol extracts of LP (IC50 $64.27 \pm 2.1 \mu \mathrm{g} / \mathrm{ml}$ ) indicated significant antioxidant activity, which was increased in a concentration-dependent manner. The results suggested that the strong antioxidant activity of extracts might be due to the presence of phenolics compounds present in the extract [33]. Recent investigation has shown that many flavonoids and related polyphenol contribute significantly to the antioxidant activity of many fruits such as red grape, vegetables and medicinal plants [34]. Methanol extracts of LP also markedly scavenge hydroxyl, hydrogen peroxide, superoxide radicals and nitric oxide as well as possesses a strong metallic reducing power, in addition to bleach $\beta$-carotene, the significant activity of LPME could be due to the presence of bioactive flavonoids. Our results agree with the results of Shukla et al. [35] during the screening of in vitro antioxidant activity and total phenolics content of ethanol leaf extract of Stevia rebaudiana Bert. Similar investigation was reported in other studies [36]. Oxidative stress was characterized by increased lipids peroxidation and altered nonenzymatic and enzymatic antioxidant. Cumulative evidence suggested that various enzymatic and nonenzymatic systems had been developed by mammalian cells to survive with ROS and other free radicals. Methanolic extracts of LP markedly reduced lipid peroxidation comparatively to other fractions and reference compounds. Other studies have similar contribution during characterization of lipids peroxidation. Previous studies have shown that Mentha extracts be able to prevent the propagation of the lipids peroxidation process in a complex lipids matrix, such as a foodstuff or biological membrane [37-39]. Flavonoids are a large group of compounds occurring ubiquitously in food plants. They occur as glycosides and contain several phenolics hydroxyl groups in their ring structure, capable of antioxidant activities [13]. In our study, flavonoids showed a concentration dependent antioxidant activity of different fractions of LP. Phenols are secondary metabolites in plants and are known to possess a wide range of therapeutic uses, such as antioxidant, antimutagenic, anticarcinogenic, free radicalscavenging and also decrease cardiovascular complications [40]. The scavenging ability of the phenols is mainly, because of the presence of hydroxyl groups. From the results obtained, it is inferred that total phenol contents were present in the reasonable amount in LPME and its derived fractions. A previous report also supports our results [41].

\section{Materials and methods \\ Chemicals}

Nitroblue tetrazolium (NBT), $\beta$-nicotinamide adenine dinucleotide reduced ( $\beta$-NADH), 2-deoxy- D-ribose, linoleic acid, ammonium thiocyanate, $\beta$-carotene, 3 -(2-pyridyl)-5, 6 bis (4-phenylsulfonic acid)-1,2,4-triazine (ferrozine), Phenazine methosulphate (PMS), 2,2-diphenyl-1-picrylhydrazyl (DPPH), ethylenediamine tetra acetic acid (EDTA), rutin, ascorbic acid, gallic acid, potassium ferricyanide; trichloroacetic acid (TCA), thiobarbituric acids (TBA) were obtained from Sigma Aldrich Chemical Co. (USA). All other reagents were of analytical grade.

\section{Plant collection}

Plants of LP at maturity were collected from Wah Cantt, city Rawalpindi (Pakistan). Plants were identified and a 
specimen was submitted at Herbarium of Pakistan, Quaid-I-Azam University Islamabad, Pakistan. Whole plant (leaves, stem, flowers and seeds) were shades dried at room temperature for two weeks, chopped, ground mechanically of mesh size $1 \mathrm{~mm}$.

\section{Preparation of plant extracts}

Five kg powder of Launaea procumbens was extracted twice in 10 liter of methanol with random shaking, after a week the extract was filtered through whatmann filter paper No. 45, filtrate was mixed and evaporated through rotary vacuum evaporator at $40^{\circ} \mathrm{C}$ to get $362 \mathrm{~g}$ methanolic crude extracts (LPME). The crude extract was suspended in water and fractionated by liquid: liquid partition with solvents of increasing polarity; starting from n-hexane (23 g; LPHE), ethyl acetate (43 g; LPEE) and chloroform (67 g; LPCE). All the fractions were stored at four ${ }^{\circ} \mathrm{C}$ for further phytochemical and in vitro investigations.

\section{Phytochemicals characterization Determination of the total phenolics contents}

Total phenolics contents (TPC) were estimated using the method of Singleton and Rossi [42]. Two hundred micro liters (1-5 mg/ml; dissolved in respective solvent) of each fraction was added in ten milliliter of 1:10 folin-ciocalteu reagent and incubated for $5 \mathrm{~min}$ before the addition of $7 \mathrm{ml}$ of $0.115 \mathrm{mg} / \mathrm{ml} \mathrm{Na} 2 \mathrm{CO}$. The resulting solution was incubated a further $2 \mathrm{~h}$ before absorbance readings were taken at $765 \mathrm{~nm}$. Gallic acid was used in the calibration curve. Results were expressed as mg gallic acid (GAE)/g dried plant extract. Data for each fraction was recorded in triplicate.

\section{Determination of the total flavonoids}

Total flavonoids content was determined by using a method described by Sakanaka et al., [43]. Briefly, $0.25 \mathrm{ml}$ of each fraction (1-5 $\mathrm{mg} / \mathrm{ml}$; dissolved in respective solvent) and rutin standard solution $(15-250 \mu \mathrm{g} / \mathrm{ml})$ was mixed with $1.25 \mathrm{ml}$ of distilled water in a test tube, followed by addition of $75 \mu \mathrm{l}$ of a $5 \%(\mathrm{w} / \mathrm{v})$ sodium nitrite solution. After $6 \mathrm{~min}, 150 \mu \mathrm{l}$ of $10 \%(\mathrm{w} / \mathrm{v})$ aluminum chloride solution was added, and the mixture was allowed to stand for a further $5 \mathrm{~min}$ before $0.5 \mathrm{ml}$ of $1 \mathrm{M} \mathrm{NaOH}$ was added. The mixture was made up to $2.5 \mathrm{ml}$ with distilled water and mixed well. The absorbance was measured immediately at $510 \mathrm{~nm}$. The results of samples were expressed as $\mathrm{mg}$ of rutin equivalents of total dried fractions. All fractions were run in triplicate.

\section{High performance liquid chromatography'}

One gram powder was extracted with $6 \mathrm{ml}$ of $25 \%$ hydrochloric acid and $20 \mathrm{ml}$ methanol for $1 \mathrm{~h}$.
The obtained extract was filtered to a volumetric flask. The residue was heated twice with $20 \mathrm{ml}$ of methanol for $20 \mathrm{~min}$. The combined extract was diluted with methanol to $100 \mathrm{ml}$. $5 \mathrm{ml}$ portion of the solution was filtered and transferred to a volumetric flask and diluted with $10 \mathrm{ml}$ of methanol. The sample $(10 \mu \mathrm{l})$ was injected into the HPLC apparatus. Samples were analyzed on Agilent HPLC. Separation was carried out through column $(5 \mu \mathrm{m}$; $4.6 \times 150 \mathrm{~mm}$, Agilent) with UV-vis detector. Solvent A (0.05\% trifluoroacetic acid) and solvent B (0.038\%trifluoroacetic acid in $83 \%$ acetonitrile $(\mathrm{v} / \mathrm{v})$ with the following gradient: $0-5 \mathrm{~min}, 15 \% \mathrm{~B}$ in $\mathrm{A}, 5-10 \mathrm{~min}, 70 \% \mathrm{~B}$ in $\mathrm{A}, 10-$ $15 \mathrm{~min}, 70 \% \mathrm{~B}$ in $\mathrm{A}$ are used for separation. The flow rate was $1 \mathrm{ml} / \mathrm{min}$ and injection volume was $10 \mu \mathrm{l}$. Six different standards compounds (myricetin, catechin, vitexin, orientin, hyperuside, and rutin) were run for comparable detection and optimized. The calibration curves were defined for each compound in the range of sample quantity $0.02-$ $0.5 \mu \mathrm{g}$. All samples were assayed in triplicate. All quantitative data were explained by analyst software.

\section{Antioxidant assays $D P P H$ radical scavenging}

The free-radical scavenging activity was measured by using 1, 1-diphenyl-2-picryl-hydrazyl (DPPH) assay. $\mathrm{DPPH}$ assay was performed according to the procedure as reported by Gyamfi et al. [44]. DPPH solution was prepared by dissolving $3.2 \mathrm{mg}$ in $100 \mathrm{ml}$ of $82 \%$ methanol. $2.8 \mathrm{ml}$ of DPPH solution was added to glass vial followed by the addition of $0.2 \mathrm{ml}$ of test sample solution, in methanol, leading to the final concentration of $1 \mu \mathrm{g} / \mathrm{ml}$, $5 \mu \mathrm{g} / \mathrm{ml}, 10 \mu \mathrm{g} / \mathrm{ml}, 25 \mu \mathrm{g} / \mathrm{ml}, 50 \mu \mathrm{g} / \mathrm{ml}$ and $100 \mu \mathrm{g} / \mathrm{ml}$. Mixture of DPPH, and each fraction was shaken well and kept in the dark at controlled room temperature $\left(25-28^{\circ} \mathrm{C}\right)$ for $1 \mathrm{~h}$. After incubation change in color was measured at $517 \mathrm{~nm}$. Mixture of $2.8 \mathrm{ml}$ of $82 \%$ methanol and $0.2 \mathrm{ml}$ of methanol were used as blank while $0.2 \mathrm{ml}$ of methanol and $2.8 \mathrm{ml}$ of DPPH solution were taken as control. The test of each fraction was performed in triplicate. Percentage inhibition was measured according to following formula and IC50 value was calculated by graph pad prism software.

$$
\begin{aligned}
\% \text { scavenging } & =\text { Abs. of control }- \text { Abs. of fraction } \\
& \times 100 / \text { Abs. of control }
\end{aligned}
$$

\section{ABTS radical cation assay}

ABTS radical cation assay was carried out using the protocol of Re et al. [45]. According to this protocol, ABTS (2, 20-azinobis-(3-ethylbenzothiazoneline-6-sulphonic acid, $7.4 \mathrm{mM}$ ) used as the free-radical provider, was treated with potassium persulfate $(2.45 \mathrm{mM})$ to produce free radicals. The solution was diluted to obtain an absorbance of 1.5- 
2.5 at $414 \mathrm{~nm}$ with $98 \%$ of ethanol, before used. Reagent (3 ml) was transferred to the glass cuvettes with one of them containing $3 \mathrm{ml}$ ethanol as blank. The initial absorbance of the reagents in the glass cuvettes was recorded at $414 \mathrm{~nm} .100 \mu \mathrm{l}$ of each fraction $(0.05-0.250 \mathrm{mg} / \mathrm{ml})$ were transferred into the cuvettes containing the reagent, and the mixtures were shaken thoroughly. The mixture in the cuvette was examined after 90 min using a UV-vis spectrophotometer. Antioxidant capacity of the ascorbic acid was also determined. The capability to scavenging the ABTS radical cation was calculated using the following equation;

$\%$ ABTS radical cation scavenging ability $=(\mathrm{A} 1-\mathrm{A} 2 / \mathrm{A} 1) \times 100$

Where A1 is the absorbance of the control (ABTS solution without test sample), and A2 is the absorbance in the presence of the test sample. The results reported are expressed as their IC50 through Graph prism pad software.

\section{Phosphomolybdenum assay}

The antioxidant activity of fractions was evaluated by phosphomolybdenum method according to the procedure of Prieto et al. [32]. An aliquot of $0.1 \mathrm{ml}$ of each fraction (dissolved in respective solvent) was combined in a vial with $1 \mathrm{ml}$ of reagent solution $(0.6 \mathrm{M}$ sulphuric acid, $28 \mathrm{mM}$ sodium phosphate and $4 \mathrm{mM}$ ammonium molybdate). The vial was capped and incubated in a water bath at $95^{\circ} \mathrm{C}$ for $90 \mathrm{~min}$. After the incubation, samples were cooled to room temperature, and the absorbance of the mixture was measured at $765 \mathrm{~nm}$ against a blank. Percent inhibition was calculated by the following formula while IC50 was calculated through Graph prism pad software. $\begin{aligned} & \% \text { inhibition }=(1-\text { absorbance of sample/absorbance of control }) \\ & \times 100\end{aligned}$

\section{Antioxidant activity by $\beta$-carotene bleaching method}

The antioxidant activity of each fraction was evaluated using the $ß$-carotene-linoleate model system, as described by Sun and Ho [46]. $2 \mathrm{mg}$ of $\beta$-carotene were dissolved in $10 \mathrm{ml}$ chloroform and $1 \mathrm{ml} \beta$-carotene solution was mixed with $20 \mathrm{mg}$ of purified linoleic acid and $200 \mathrm{mg}$ of Tween 40 emulsifiers. Chloroform was then evaporated under a gentle stream of nitrogen, and the resulting mixture was immediately diluted with $50 \mathrm{ml}$ of distilled water. To an aliquot of $5 \mathrm{ml}$ of this emulsion, $0.2 \mathrm{ml}$ of each extract $(0.05-0.250 \mathrm{mg} / \mathrm{ml})$ or ascorbic acids were added and mixed well. The absorbance at $470 \mathrm{~nm}$, which was regarded as $\mathrm{t} 0$, was measured, immediately, against a blank consisting of the emulsion without $\beta$-carotene. The capped tubes were placed in a water bath at $50^{\circ} \mathrm{C}$, and the absorbance was measured after every $15 \mathrm{~min}$ up to $120 \mathrm{~min}$. For the positive control, sample was replaced with ascorbic acid. A negative control consisted of $0.2 \mathrm{ml}$ of distilled water or solvent instead of extract or reference antioxidant was used. All samples were assayed in triplicate. The antioxidant activity (AA) was measured in terms of successful bleaching of $\beta$-carotene by using the following equation; $\mathrm{AA}=((1-(\mathrm{A} 0-\mathrm{At} / \mathrm{A} 0-\mathrm{A} 0 \mathrm{t})) \times 100$

Where $\mathrm{A} 0$ and $\mathrm{A} 0$ are the absorbance values measured at zero times during the incubation for each fraction and control, respectively. At an A0t was the absorbance values measured for each fraction and control, respectively, after incubation for $120 \mathrm{~min}$. The results were expressed as IC50.

\section{Superoxide radical scavenging activity}

Superoxide radical scavenging activity of each fraction was determined by the nitroblue tetrazolium reduction method [47]. One milliliter of nitroblue tetrazolium (NBT) solution (l M NBT in $100 \mathrm{mM}$ phosphate buffer, $\mathrm{pH} 7.4$ ), $1 \mathrm{ml}$ $\mathrm{NADH}$ solution (1 M NADH in $100 \mathrm{mM}$ phosphate buffer, $\mathrm{pH} 7.4)$ and $0.1 \mathrm{ml}$ of the extracts $(0.50-0.250 \mathrm{mg} / \mathrm{ml})$ and ascorbic acid (0.050-0.250 mg/ml) were mixed. The reaction was started by adding $100 \mu \mathrm{l}$ of PMS solution $(60 \mu \mathrm{M}$ PMS in $100 \mathrm{mM}$ phosphate buffer, $\mathrm{pH} 7.4$ ) to the mixture. The reaction mixture was incubated at $25^{\circ} \mathrm{C}$ for $5 \mathrm{~min}$, and the absorbance at $560 \mathrm{~nm}$ was measured against blank samples, containing all the reagents except the PMS. The positive and negative controls were subjected to the same procedures as the sample, except that for the negative control, only the solvent was added, and for the positive control, sample was replaced with ascorbic acid. All measurements were made in triplicate. The abilities to scavenge the superoxide radical were calculated using the following equation;

$$
\begin{aligned}
& \begin{array}{r}
\% \text { superoxide radical } \\
\text { scavenging activity }=
\end{array} \begin{array}{r}
\text { absorbance of sample at } 560 \mathrm{~nm} / \\
\text { absorbance of control at } 560 \mathrm{~nm})
\end{array} \\
& \times 100
\end{aligned}
$$

IC50 was calculated through software.

\section{Hydroxyl radical scavenging activity}

The effect of extracts on hydroxyl radicals was assayed by using the deoxyribose method [48]. Solution of each fraction and ascorbic acid (ASA) was prepared in methanol. The reaction mixture contained; $450 \mu \mathrm{l}$ of $0.2 \mathrm{M}$ sodium phosphate buffer (pH 7.0), $150 \mu \mathrm{l}$ of $10 \mathrm{mM} 2$ - deoxyribose, $150 \mu \mathrm{l}$ of $10 \mathrm{mM} \mathrm{FeSO}_{4}$-EDTA, $150 \mu \mathrm{l}$ of $10 \mathrm{mM}$ $\mathrm{H}_{2} \mathrm{O}_{2}, 525 \mu \mathrm{l}$ of $\mathrm{H}_{2} \mathrm{O}$, and $75 \mu \mathrm{l}$ of sample solution (0.050$0.250 \mathrm{mg} / \mathrm{ml}$ ). The reaction was started by the addition of $\mathrm{H}_{2} \mathrm{O}_{2}$. After incubation at $37^{\circ} \mathrm{C}$ for $4 \mathrm{~h}$, the reaction was stopped by adding $750 \mu \mathrm{l}$ of $2.8 \%$ trichloroacetic acid and $750 \mu \mathrm{l}$ of $1 \% \mathrm{TBA}$ in $50 \mathrm{mM} \mathrm{NaOH}$, the solution was boiled for $10 \mathrm{~min}$, and then cooled in water. The absorbance of the solution was measured at $520 \mathrm{~nm}$. Ascorbic 
acid $(0.05-0.250 \mathrm{mg} / \mathrm{ml})$ was used as positive controls. The ability to scavenge the hydroxyl radical was calculated using the following equation;

$$
\begin{aligned}
& \% \text { superoxide radical scavenging activity } \\
& =(1-\text { absorbance of sample/absorbance of control }) \times 100
\end{aligned}
$$

\section{Hydrogen peroxide-scavenging activity}

The ability of the extracts to scavenge hydrogen peroxide was determined according to the method of Ruch et al. [49]. A solution of hydrogen peroxide $(2 \mathrm{mM})$ was prepared in $50 \mathrm{mM}$ phosphate buffer ( $\mathrm{pH}$ 7.4). Hydrogen peroxide concentration was determined spectrophotometrically at $230 \mathrm{~nm}$ absorption, using the molar extinction coefficient for $\mathrm{H}_{2} \mathrm{O}_{2}$ of $81 \mathrm{~mol}^{-1} \mathrm{~cm}^{-1}$. Samples of various fractions $(0.050-0.250 \mathrm{mg} / \mathrm{ml})$ and ascorbic acid (0.05$0.250 \mathrm{mg} / \mathrm{ml}$ ) were transferred into the test tubes, and their volumes were made up to $0.4 \mathrm{ml}$ with $50 \mathrm{mM}$ phosphate buffer ( $\mathrm{pH}$ 7.4). After addition of $0.6 \mathrm{ml}$ hydrogen peroxide solution, tubes were vortex and absorbance of the hydrogen peroxide at $230 \mathrm{~nm}$ was determined after $10 \mathrm{~min}$, against a blank. $50 \mathrm{mM}$ phosphate buffer without hydrogen peroxide was used as blank. Hydrogen per oxide scavenging ability was calculated by following equation:

$$
\begin{aligned}
& \text { Hydrogenperoxidescavengingactivity } \\
& \quad=(1-\text { absorbanceofsample/absorbanceofcontrol }) \times 100
\end{aligned}
$$

IC50 was calculated through graph prism pad software.

\section{Chelating activity on Fe2+}

The extracts were assessed for their ability to compete with ferrozine for iron (II) ions in free solution. The chelating ability of ferrous ions by various fractions was estimated by the method of Dinis et al. [50]. Extracts $(0.05-250 \mathrm{mg} / \mathrm{ml})$, $2.5 \mathrm{ml}$ were added to a solution of $2 \mathrm{mM} \mathrm{FeCl}_{2} .4 \mathrm{H}_{2} \mathrm{O}$ $(0.05 \mathrm{ml})$. The reaction was initiated by the addition of $5 \mathrm{mM}$ ferrozine $(0.2 \mathrm{ml})$; the mixture was shaken vigorously and left standing at room temperature for $10 \mathrm{~min}$. Absorbance of the solution was then measured at $562 \mathrm{~nm}$ against the blank performed in the same way using $\mathrm{FeCl}_{2}$ and water. EDTA $(0.625-5 \mu \mathrm{g} / \mathrm{ml})$ served as the positive control, and a sample without extract or EDTA served as the negative control. All tests were run in triplicate and averaged. The percentage of inhibition of ferrozine-Fe ${ }^{2}+$ complex formation was calculated using the formula:

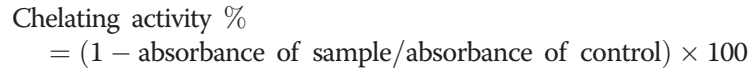

\section{Lipid peroxidation assay}

Lipid peroxidation assay was performed according to modified protocol of Banerjee et al. [51] to measure the lipid peroxide formed, using egg yolk homogenates as lipid-rich media [52]. Egg homogenate $(0.5 \mathrm{ml}$ of $10 \%, \mathrm{v} / \mathrm{v})$ and $0.1 \mathrm{ml}$ of each fraction and ascorbic acid (0.5$0.250 \mathrm{mg} / \mathrm{ml}$ ) was dissolved in respective solvent; were added to a test tube and made up to $1 \mathrm{ml}$ with distilled water. $0.05 \mathrm{ml}$ of $\mathrm{FeSO}_{4}(0.07 \mathrm{M})$ was added to induce lipid peroxidation and incubated for $30 \mathrm{~min}$. Then $1.5 \mathrm{ml}$ of $3.5 \mathrm{M}$ acetic acid ( $\mathrm{pH}$ adjusted to 3.5 with $\mathrm{NaOH}$ ) and $1.5 \mathrm{ml}$ of $0.06 \mathrm{M}$ TBA in $0.04 \mathrm{M}$ sodium dodecyl sulphate and $0.05 \mathrm{ml}$ of $1.2 \mathrm{M}$ of TCA was added, and the resulting mixture was vortex and then heated at $95^{\circ} \mathrm{C}$ for $60 \mathrm{~min}$. To eliminate this non-MDA interference, another set of samples was treated in the same way, incubating without TBA, to subtract the absorbance for fraction and reference compounds. After cooling, $5 \mathrm{ml}$ of butan-1-ol was added to each tube and centrifuged at $3000 \times \mathrm{g}$ for $10 \mathrm{~min}$. The absorbance of the organic upper layer was measured at $532 \mathrm{~nm}$. Inhibition of lipid peroxidation (\%) by the sample was calculated according to the following formula:

\%inhibition $=(1-\mathrm{E} / \mathrm{C}) \times 100$

Where $C$ is the absorbance value of the fully oxidized control, and $\mathrm{E}$ is $\{(\mathrm{A} 532+\mathrm{TBA})-(\mathrm{A} 532-\mathrm{TBA})\}$.

\section{Nitric oxide scavenging activity}

The nitric oxide scavenging activity was conducted based upon the method by Rai et al. [53]. $0.5 \mathrm{ml}$ of $10 \mathrm{mM}$ sodium nitroprusside in phosphate bufferedsaline was mixed with $0.5 \mathrm{ml}$ of different concentrations of the various fractions and control and incubated in the dark at room temperature for $150 \mathrm{~min}$. After the incubation period, $1 \mathrm{ml}$ of sulfanilic acid reagent $(0.33 \%$ sulfanilic acid in $20 \%$ glacial acetic acid) was added to $0.5 \mathrm{ml}$ of the reaction mixture. After $5 \mathrm{~min}$ incubation, $1 \mathrm{ml}$ of $0.1 \%$ naphthyl ethylene diamine dihydrochloride was added and incubated for $30 \mathrm{~min}$ at $25^{\circ} \mathrm{C}$. The absorbance of the chromophore formed was read at $540 \mathrm{~nm}$. Ascorbic acid was used as positive control and results were expressed as percentage inhibition of nitric oxide. The nitric oxide scavenging activity of the extracts was also measured using the Trolox standard curve and results were expressed as $\mathrm{mM}$ Trolox equivalent antioxidant capacity (TEAC) per g dried fraction. All determinations were performed in triplicates.

\section{Statistical analysis}

All assays were carried out in triplicates, and results are expressed as mean $\pm \mathrm{SD}$. ANOVA test was used to analyze the differences among IC50 of various fractions for different antioxidant assays, with least significance difference (LSD) $P<0.01$ as a level of significance. Experimental results were further analyzed for Pearson's correlation coefficient of phenolics, flavonoids with different antioxidant assays and tested for significance by 
student's test $(P<0.05 ; P<0.01)$. The IC50 values were calculated using graph pad prism software.

\section{Conclusion}

The results obtained in this study have considerable value with respect to the antioxidant activities of LPME. The presence of these activities is attributed to the phenolics and poly phenolics compounds such as myricetin, catechin, vitexin, orientin, hyperoside, and rutin, revealed in HPLC. Our results suggested that the extract can be utilized as an effective and safe antioxidant source, as ethnomedicine and on a commercial basis for the development of drugs.

\section{Competing interest}

The authors declare that they have no competing interests.

\section{Authors' contributions}

RAK made a significant contribution to acquisition of data, analysis, drafting of the manuscript. MRK and SS has made a substantial contribution to conception and design, interpretation of data, drafting and revising the manuscript for intellectual content. All authors read and approved the final manuscript.

\section{Author details}

${ }^{1}$ Department of Biotechnology, Faculty of Biological Sciences, University of Science and Technology, Bannu, KPK 28100, Pakistan. ${ }^{2}$ Department of Biochemistry, Faculty of Biological Sciences, Quaid-I-Azam University Islamabad, Islamabad, Pakistan. ${ }^{3}$ Botanical Sciences Division, Pakistan Museum of Natural History, Garden Avenue, Shakarparian, Islamabad, Pakistan.

Received: 15 February 2012 Accepted: 4 May 2012

Published: 22 May 2012

\section{References}

1. Halliwell B, Gutteridge JMC: Oxygen toxicity, oxygen radicals, transition metals and disease. J Biochem 1984, 219:1-14

2. Fritz KL, Seppanen CM, Kurzer MS, Csallany AS: The in vivo antioxidant activity of soybean isoflavone in human subjects. Nut Res 2003, 23:479-487.

3. Patricia I, Oteiza AG, Erlejman S, Verstraeten V, Keen CL, Fraga CS: Flavonoid membrane interactions: A protective role of flavonoids at the membrane surface. Clin Develop Immunol 2005, 12:23-25.

4. Ames SN, Shigrenaga MK, Hagen TM: Oxidant, antioxidant and degradative disease of aging. Proc Nat Acad Sci USA 1993, 90:7915-7922.

5. Robak J, Gryglewski RJ: Flavonoids are scavengers of superoxides anions. Biochem Pharmacol 1988, 37:837-841.

6. Ardestani $A$, Yazdanparast $R$ : Antioxidant and free radical scavenging potential of Achillea santolina extracts. Food Chem 2007, 104:21-29.

7. Bingham M, Gibson G, Gottstein N, Pascual-Teresa SD, Minihane AM, Rimbach G: Gut metabolism and cardio protective effects of dietary isoflavones. Current Top Nut Res 2003, 1:31-48.

8. Silva BM, Andrade PB, Valentãoo P, Ferreres F, Seabra RM, Ferreira MA Quince (Cydonia oblonga Miller) fruit (pulp, peel, and seed) and jam: antioxidant activity. J Agric Food Chem 2004, 52:4705-4712.

9. Wazir SM, Saima S, Dasti AA, Subhan S: Ethanobotnical importance of salt range species of district karak, Pakistan. Pakistan J Plant Sci 2007, 13:29-31.

10. Ahmad M, Khan MA, Manzoor S, Zafar M, Sultana S: Check list of medicinal flora of Tehsil Isakhel, District Mianwali Pakistan. Ethnobotanical Leaflets 2006, 10:41-48.

11. Shaukat SS, Siddiqui IA, Nasim Al: Nematocidal, Allelopatic and antifugal potential of Launaea procumbens. Pakistan J Plant Pathol 2003, 2:181-19313.

12. Singh $R$, Singh $S$, Kumar $S$, Arora S: Evaluation of antioxidant potential of ethyl acetate extract/fractions of Acacia auriculiformis A. Cunn Food Chem Toxicol 2007, 45:1216-1223.

13. Cao G, Sofic E, Prior RL: Antioxidant and pro-oxidant behavior of flavonoids: Structure activity relationships. Free Rad Biol Med 2009, 22:749-760.
14. Khan RA, Khan MR, Sahreen S: Evaluation of Launaea procumbens use in renal disorders: A rat model. J Ethanopharmacol 2010, 128:452-461.

15. Zu Y, Fu Y, Liu W, Hou C, Kong Y: Simultaneous determination of four flavonoids in Pigeonpea [Cajanus cajan (L.) Millsp.] leaves using RP-LC-DAD. Chromatographia 2006, 63:9-10.

16. Wijeratne SS, Abou-Zaid MM, Shahidi F: Antioxidant polyphenols in almond and its coproducts. JAgric Food Chem 2006, 54:312-318.

17. Liyana-Pathirana CM, Shahidi F: Importance of insoluble-bound phenolics to antioxidant properties of wheat. J Agric Food Chem 2006, 54:1256-1264.

18. Shahidi F, Alasalvar C, Liyana-Pathirana CM: Antioxidant phytochemicals in hazelnut kernel (Corylus avellana L.) and hazelnut byproduct. J Agric Food Chem 2007, 55:1212-1220.

19. Langley-Evans C: Antioxidant potential of black and green tea determined using the ferric reducing power (FRAP) assay. Int/ J Food Sci Nut 2000, 51:181-188.

20. Amaorwicz R, Troszynska A, Shahidi F: Antioxidant activity of almond seed extract and its fractions. J Food Lipids 2005, 12:344-358.

21. Liu RH: Health benefits of fruits and vegetables are from additive and synergistic combination of phytochemical. Am J Clin Nut 2003, 78:517-520.

22. Alasalvar C, Karamac M, Amarowicz R, Shahidi F: Antioxidant and antiradical activities in extracts of hazelnut kernel (Corylus avellana L.) and hazelnut green leafy cover. J Agric Food Chem 2006, 54:4826-4832.

23. Finkel T: Oxidants, oxidative stress, and the biology of aging. Nature (London) 2009, 408:239-248.

24. Scalbert A, Johnson I, Saltmarsh M: Polyphenols: Antioxidants and beyond. Am J Clin Nut 2005, 81:2155-2175.

25. Gorinstein S, Martin-Belloso O, Katrich E, Lojek A, CIz M, Gligelmo-Miguel N: Comparison of the contents of the main biochemical compounds and the antioxidant activity of some Spanish olive oils as determined by four different radical scavenging tests. J Nut Biochem 2003, 14:154-159.

26. Maisuthisakul P, Suttajit M, Pongsawatmanit R: Assessment of phenolic content and free radical-scavenging capacity of some Thai indigenous plants. Food Chem 2007, 100:1409-1418.

27. Bortolomeazzi R, Sebastianutto N, Toniolo R, Pizzariello A: Comparative evaluation of the antioxidant capacity of smoke flavouring phenols by crocin bleaching inhibition, DPPH radical scavenging and oxidation potential. Food Chem 2007, 100:1481-1489.

28. Chung KT, Wong TY, Huang YW, Lin Y: Tannins and human health: a review. Critical Revw Food Sci Nut 1998, 38:421-464.

29. Topcu UG, Ulubelen A: Structure elucidation of organic compounds from natural sources using 1D and 2D NMR techniques. J Mol Struc 2009, 834:57-73.

30. Oszmianski J, Wolniak M, Wojdylo A, Wawer I: Comparative study of polyphenolic content and antiradical activity of cloudy and clear apple juices. J Sci Food Agric 2007, 87:573-579.

31. Hagerman AE, Riedl KM, Jones GA, Sovik KN, Ritchard NT, Hartzfeld PW: High molecular weight plant polyphenolics (tannins) as biological antioxidants. J Agric Food Chem 1998, 46:1887-1892.

32. Prieto P, Pineda M, Aguilar M: Spectophotometric quantitation of antioxidant capacity through the formation of a phosphomolybdenum complex: Specific application to the determination of vitamin E. Anal Biochem 2005, 269:337-341.

33. Falleh H, Ksouri R, Chaieb K, Karray-Bouraoui N, Trabelsi N, Boulaaba M, Abdelly C: Phenolic composition of Cynara cardunculus L. organs, and their biological activities. Comp Rend Biol 2008, 331:372-379.

34. Bourgou S, Ksouri R, Bellila A, Skandrani I, Falleh H, Marzouk B: Phenolic composition and biological activities of Tunisian Nigella sativa L. shoots and roots. Compte Rendu de Biologies 2008, 331:48-55.

35. Shukla S, Mehta M, Bajpai VK, Shukla S: In vitro antioxidant activity and total phenolic content of ethanolic leaf extract of Stevia rebaudiana Bert. Food Chem Toxicol 2009, 47:2338-2343.

36. Razali N, Razab R, Junit SM, Aziz AA: Radical scavenging and reducing properties of extracts of cashew shoots (Anacardium occidentale). Food Chem 2008, 111:38-44.

37. Dorman HJ, Kosar M, Kahlos K, Holm Y, Hiltunen R: Antioxidant properties and composition of aqueous extracts from Mentha species, hybrids, varieties, and cultivars. J Agric Food Chem 2003, 51:4563-4569.

38. Mimica-Dukic N, Bozin B, Sokovic M, Mihajlovic B, Matavulj M: Antimicrobial and antioxidant activities of three Mentha species essential oils. Planta Medica 2003, 69:413-419. 
39. Conforti F, Sosa S, Marrelli M, Menichini F, Statti GA, Uzunov D, Tubaro A, Menichini A, Loggia RD: In vivo antiinflammatory and in vitro antioxidant activities of Mediterranean dietary plants. J Ethnopharmacol 2008, 116:144-151.

40. Yen GC, Duh PD, Tsai CL: Relationship between antioxidant activity and maturity of peanut hulls. J Agric Food Chem 1993, 41:67-70.

41. Aqil F, Ahmad I, Mehmood Z: Antioxidant and free radical-scavenging properties of twelve traditionally used Indian medicinal plants. Turk J Biol 2006, 30:177-183.

42. Singleton $V L$, Rossi $J A$ : Colorimetry of total phenolics with phosphomolybdic-phosphotungstic acid reagents. Am J Enol Viticulture 1996, 16:144-153.

43. Sakanaka S, Tachibana Y, Okada Y: Preparation and antioxidant properties of extracts of Japanese persimmon leaf tea (kakinoha-cha). Food Chem 2005, 9:569-575.

44. Gyamfi MA, Yonamine M, Aniya Y: Free radical scavenging activity of medicinal herb of Ghana: Thonningia sanguinea on experimentally induced liver injuries. Gen Pharmacol 1999, 32:661-667.

45. Re R, Pellegrini N, Proteggente A, Pannala A, Yong M, Rice-Evas C: Antioxidant activity applying an improved $A B T S$ radical cation decolorusation assay. Free Rad Biol Med 1999, 26(9/10):1231-1237.

46. Sun T, Ho CT: Antioxidant activities of buckwheat extracts. Food Chem 2005, 90:743-749.

47. Nishikimi M, Rao NA, Yagi K: The occurence of superoxide anion in the reaction of reduced phenazine methosulfate and molecular oxygen. Biochem Biophys Res Commun 1972, 46:849-854.

48. Nagai T, Myoda T, Nagashima T: Antioxidative activities of water extract and ethanol extract from field horsetail (tsukushi) Equisetum arvense L. Food Chem 2005, 91:389-394.

49. Ruch RJ, Cheng SJ, Klaunig JE: Prevention of cytotoxicity and inhibition of intercellular communication by antioxidant catechin isolated from Chinese green tea. Carcinogenesis 1989, 10:1003-1008.

50. Dinis TCP, Madeira VMC, Almeida LM: Action of phenolic derivatives (acetaminophen, salicylate and 5-aminosalicylate) as inhibitors of membrane lipid peroxidation and as peroxyl radical scavengers. Arch Biochem Biophys 1994, 315:161-169.

51. Banerjee A, Dasgupta N, De B: In vitro study of antioxidant activity of Syzygium cumini fruit. Food Chem 2005, 90:727-733.

52. Ruberto G, Baratta MT, Deans SG, Dorman HJD: Antioxidant and antimicrobial activity of Foeniculum vulgare and Crithmum maritimum essential oils. Planta Medica 2000, 66:687-693.

53. Rai S, Wahile A, Mukherjee K, Saha BP, Mukherjee PK: Antioxidant activity of Nelumbo nucifera (sacred lotus) seeds. J Ethnopharmacol 2006, 104:322-327.

Cite this article as: Khan et al:: Assessment of flavonoids contents and in vitro antioxidant activity of Launaea procumbens. Chemistry Central Journal 2012 6:43.

Publish with ChemistryCentral and every
scientist can read your work free of charge
"Open access provides opportunities to our
colleagues in other parts of the globe, by allowing
anyone to view the content free of charge."
W. Jeffery Hurst, The Hershey Company.
- available free of charge to the entire scientific community
- peer reviewed and published immediately upon acceptance
- cited in PubMed and archived on PubMed Central
- yours - you keep the copyright
Submit your manuscript here:
http://www.chemistrycentral.com/manuscript/

